CLINICAL STUDY

\title{
Serum leptin and C-reactive protein levels in the physiological spontaneous menstrual cycle in reproductive age women
}

\author{
D M Wunder ${ }^{1}$, M Yared ${ }^{1}$, N A Bersinger ${ }^{1}$, D Widmer ${ }^{1}$, R Kretschmer $^{2}$ and M H Birkhäuser ${ }^{1}$ \\ ${ }^{1}$ Department of Obstetrics and Gynaecology, University of Berne, Switzerland and ${ }^{2}$ Central Laboratory, Inselspital, Switzerland \\ (Correspondence should be addressed to D M Wunder; Universitäts-Frauenklinik, Inselspital, Effingerstrasse 102, Berne, CH-3010, Switzerland; Email: \\ dorothea.wunder@insel.ch)
}

\begin{abstract}
Objective: Only a few studies have investigated variations of different markers for inflammatory processes during the physiological menstrual cycle. The results are conflicting, particularly concerning the correlation between the marker leptin and steroid hormones. The aim of the study was to investigate the inflammatory markers C-reactive protein (CRP) and leptin in the serum of healthy, normally ovulating women and to correlate these with each other and with the hormones of the gonadal axis. A cycle-dependence of the markers studied would imply an exact timing of the blood sampling for clinical needs.

Design: Observational study investigating the two inflammatory markers CRP and leptin in relation to the hormonal pattern of the gonadal axis during the normal cycle.

Methods: Ovulatory cycles of 36 healthy, young, normo-androgenic women, having a normal body mass index were evaluated. Serum concentrations of leptin and CRP, as well as of follicle-stimulating hormone, luteinising hormone, 17 $\beta$-oestradiol, progesterone, prolactin (PRL) and free testosterone were measured every 1-2 days during one full cycle.

Results: Serum levels of leptin and CRP behaved differently during ovulatory cycles, with higher concentrations for leptin only during certain phases. Significant correlations were found in the follicular phase between leptin and PRL and leptin and free testosterone.

Conclusions: Leptin levels change during the menstrual cycle. Leptin levels are more stable on cycle days 1-5 than later in the cycle. For precise cycle-independent measurements, these fluctuations have to be taken into account. There is no similar cyclic pattern for CRP.
\end{abstract}

European Journal of Endocrinology 155 137-142

\section{Introduction}

Leptin is a hormone encoded by the obesity $(o b)$ gene. Initially, it was found to have anti-obesity effects, but then it has been shown to have also immunoregulatory (1), pro-inflammatory $(2)$ and angiogenic $(1,3)$ properties. Influences on reproduction (4) and involvement in the pathogenesis of endometriosis (5) and infertility $(6,7)$ have also been demonstrated. Concentrations of circulating leptin are increased by inflammatory mediators (8). Results published on serum leptin levels during the physiological menstrual cycle vary considerably. Some studies showed significant increase in the late follicular phase $(9,10)$, and some did so on the day of the onset of the luteinising hormone (LH) surge $(11,12)$. Other investigations described significant increase in serum leptin levels in the late luteal phase (13-17), and again others reported only small, not statistically significant variations during the menstrual cycle (18-21). The acute phase C-reactive protein (CRP) is produced by the liver. A strong correlation has been found between the body mass index (BMI) and both leptin and CRP levels (22-25). Shamsuzzaman et al. (26) showed an association between plasma CRP and leptin in men and non-pregnant women, and Bullo et al. (27) even demonstrated that leptin could induce the production of CRP. Maruna et al. (28) confirmed the correlation between CRP and leptin, and identified the latter as an acute phase reactant with potential haematopoietic, immunomodulatory, and hepatocytestimulating activity. To our knowledge only two studies have been published to date investigating CRP levels during the physiological menstrual cycle: in a small sample of patients, Jilma et al. (29) found increased CRP concentrations at midcycle and in the luteal phase, with a significant correlation with progesterone levels. Blum et al. (30) also reported varying CRP concentrations during the menstrual cycle. As ovulation is an inflammatory process, the interactions and correlations between leptin, CRP and the gonadal hormones in the physiological menstrual cycle are of great interest in this context. To the best of our knowledge, no longitudinal studies comparing these two acute phase reactants in the normal menstrual cycle have been performed 
yet; and generally only a small body of information on CRP in reproduction is currently available. The aim of the present study was to examine, in the physiological menstrual cycle, whether leptin and CRP, which are both involved in inflammatory processes, are correlated with each other and with the other hormones of the pituitary-gonadal axis. If there would be a correlation with cycle-dependent hormones such as oestradiol (E2), progesterone or androgens, clinical recommendations would be needed concerning the timing of the blood sampling of inflammatory factors within the cycle. Otherwise, a misinterpretation of cycle-dependent values would be possible, with potentially serious clinical consequences.

\section{Materials and methods}

\section{Evaluation of volunteers}

The present study was conducted amongst 36 Caucasian women. They were recruited through advertising at the University campus and most of them were students. They were aged between 20 and 32 years, reported regular menstrual cycles and had not been taking oral contraceptives or other medicines for at least 3 months. Other inclusion criteria were a good health status, a normal (18.5-25 kg/m²) BMI and normal pretreatment hormonal values for follicle-stimulating hormone (FSH), LH, prolactin (PRL), 17 $\beta$-E2, free testosterone and dehydro epiandrosterone sulphate. In addition, haematological and chemical laboratory analyses, a physical examination, and the results from a gynaecological ultrasound and a Papanicolou (PAP) cervical smear had to be normal. Therefore, women with polycystic ovary syndrome have been excluded. Finally, a biphasic pattern of the basal body temperature (BBT) was required. All examinations were performed prior to the collection of blood from the subjects for the study cycle. Primary criteria for exclusion were pregnancy, dysovulation with a monophasic BBT chart and a short luteal phase, use of medicines, or inaccessibility of follow-up. The investigation was approved by the ethical committee of the University of Berne, and written informed consent was obtained from each volunteer prior to involvement in the project.

\section{Collection of sera}

Blood samples were obtained by venipuncture, using 21-gauge needles and $9 \mathrm{ml}$ serum monovettes. All blood samples were drawn, after an overnight fast, between 0600 and 1000 h every second day from the onset of the cycle and during the whole follicular phase, until 2-5 days before ovulation. From then, samples were drawn on each day until 4 days after ovulation had taken place. Ovulation was monitored by performing five to eight urinary LH detection tests (Today-Ovulation Test; Ultimate Products Gabmed, Ahrensburg, Germany) from the late follicular phase. During the luteal phase and until the end of the cycle (onset of menstruation), blood samples were again taken every second day. Thus, in one ovulatory cycle, 14-19 (mean 16) samples per volunteer could be collected depending on the length of the cycle. Every participant registered her own morning BBT 1-4 months prior to the beginning as well as during the study cycle. The collected blood was allowed to clot and centrifuged within 60 min after venipuncture, and the obtained serum was divided into $1 \mathrm{ml}$ aliquots and stored at $-80^{\circ} \mathrm{C}$.

\section{Measurement of leptin, CRP, gonadotrophins, and steroid hormones in serum}

Leptin was quantified with a microplate enzyme immunoanalytical method (ELISA) developed in our laboratory (32) using a matched pair of MABs (R\&D Systems Europe; Abingdon, England). The samples were diluted 1:50 in PBS containing 0.5\% non-fat milk proteins (Blotto; Pierce, USA; obtained from Socochim; Lausanne, Switzerland). Subsequent incubations were as described (32). The determination of leptin after frozen storage has been validated (32). Intra- and interassay coefficients of variance for leptin were 2.7 and $8.9 \%$, respectively. CRP was also measured manually, according to our recently published immunoanalytic method (33). The initial sample dilution was 1:250, which sometimes had to be readjusted to a higher or lower factor. With $0.5 \mathrm{ng} / \mathrm{ml}$, the sensitivity of the assay was higher than the one of currently used nephelometric methods; the lowest CRP concentration measured in this study was $66 \mathrm{ng} / \mathrm{ml}$. Intra- and inter-assay coefficients of variance for CRP were 3.1 and $5.5 \%$, respectively. All other hormones (FSH, LH, E2, progesterone, free testosterone, PRL) were determined in the central routine laboratory of the University hospital, by means of the automated Elecsys 2010 method (Roche).

\section{Statistical methods}

Comparisons between the medians of marker levels at the early follicular, ovulatory, or midluteal stage were made non-parametrically using the Mann-Whitney $U$-test. Associations between these concentrations were investigated non-parametrically by Spearmanrank correlation analysis, and those between leptin with the BMI by linear regression.

\section{Results}

\section{Clinical data}

Clinical parameters of the volunteers are given in Table 1. The population was very homogeneous in terms of age, BMI, basal FSH levels, and length of the menstrual cycle. 
Table 1 Clinical parameters of the volunteers. Values given are means \pm S.D.

\begin{tabular}{lr}
\hline Clinical parameter & \multicolumn{1}{c}{ Values } \\
\hline Age $(\mathrm{yrs})$ & $25.5 \pm 5.5$ \\
Body mass index $\left(\mathrm{kg} / \mathrm{m}^{2}\right)$ & $21.9 \pm 3.1$ \\
Basal FSH (mlU/ml) & $7.1 \pm 1.9$ \\
Cycle length (days) & $28.7 \pm 6.7$ \\
\hline
\end{tabular}

\section{Steroid hormone, leptin and CRP concentrations in the sera}

Hormonal values at the different phases of the spontaneous cycle Cross-sectional results are given in Table 2 for the early follicular phase, the day of ovulation, and the midluteal phase. On the day of ovulation, sera from all subjects were available; for the other two time points, they were combined for the days -12 and -11 , or for the days +7 and +8 , respectively, thus yielding a value for each subject (see Methods). Median leptin levels were significantly higher in the midluteal than in the early follicular phase $(P=0.042)$. Leptin levels strongly correlated with the BMI independent of the cycle stage $(r>0.63$, $P<0.0001$ in all three groups). No significant differences in CRP concentrations were observed between the three time points in the cycle. This did not change after correction of the CRP concentrations for BMI (data not shown).

Time course of leptin and CRP concentrations during the spontaneous cycle Leptin levels were lowest on the first and the last day of the cycle and reached their maximum in the midluteal phase (Day +7 , Fig. 1). CRP level patterns showed no significant change during the cycle (Fig. 2). The mean values ranged between 200 and $4000 \mathrm{ng} / \mathrm{ml}$. Three subjects showed isolated extremely high and clinically unexplained spiking levels of CRP from one sampling to the next reaching $60000 \mathrm{ng} / \mathrm{ml}$ and dropping again immediately to normal levels. These erratic patterns were excluded from further analysis. However, it has to be stressed that no significant difference could be found between the cycle pattern of the 36 women before exclusion of the spiking CRP levels (data not shown) and the remaining 33 women.

Correlations between leptin and CRP levels, steroid hormones, FSH, and PRL Significant correlations were observed in the follicular phase between leptin and $\operatorname{PRL}(P=0.028)$, leptin and free testosterone $(P=0.005)$, and between CRP and free testosterone $(P<0.001)$. Spearman's rank-correlation analysis showed no correlations between CRP and leptin, either in the follicular (day -16 to -3 ) (243 sera), periovulatory (day -2 to +2 ) (159 sera, $P>0.1$ for both), or luteal phase (day +3 to +15$)(199$ sera, $P=0.079)$. The ovarian steroid hormones (E2, progesterone) did not show any correlations with leptin or CRP. In the luteal phase, no correlations between any pair of markers were found.

\section{Discussion}

Endocrine diagnosis in women depends on the exact knowledge of cyclic fluctuations of the hormones measured. The aim of the present study was to explore the possibility of cycle-dependent fluctuations of leptin and of the inflammatory marker CRP. In daily routine, this knowledge is particularly important for CRP, a frequently used clinical marker. The results published to date on leptin levels in the menstrual cycle differ remarkably. Some studies showed significant increase of leptin in the late follicular phase $(9,10)$, some on the day of the LH surge onset $(11,12)$, while others in the late luteal phase (13-17). Further studies reported small, non-significant variations during the menstrual cycle (18-21). Regarding the correlations between leptin and other hormones, similar inconsistencies

Table 2 Leptin, CRP, gonadotrophins, PRL and ovarian steroid hormone concentrations in the serum of 36 subjects during a normal ovulatory cycle. Values (medians and range) are given for the early follicular (day LH $-12 /-11$ ), midcycle (day LH), and the midluteal phase (day LH $+7 /+8)$.

\begin{tabular}{lccc}
\hline & & \multicolumn{3}{c}{ Cycle phase } & \\
\cline { 2 - 4 } Marker or hormone & Early follicular & Day LH & Midluteal \\
\hline Leptin $(\mathrm{ng} / \mathrm{ml})$ & $12.9(3.9-37.5)$ & $13.8(5.4-57.0)$ & $17.6(5.8-53.2) \dagger$ \\
Leptin/BMl & $0.64(0.22-1.54)$ & $0.62(0.26-2.34)$ & $0.84(0.25-2.25) \dagger$ \\
CRP $(\mathrm{ng} / \mathrm{ml})$ & $2313(254-8265)$ & $1817(232-7078)$ & $1883(245-5921)$ \\
FSH $(\mathrm{mlU} / \mathrm{ml})$ & $7.30(3.40-12.00)$ & $13.10(3.53-25.30)$ & $3.16(1.19-6.04)$ \\
LH $(\mathrm{mlU} / \mathrm{ml})$ & $5.06(2.46-15.80)$ & $40.3(13.8-89.7)$ & $5.54(0.16-20.80)$ \\
Prolactin $(\mathrm{ng} / \mathrm{ml})$ & $27.3(5.64-79.8)$ & $31.0(10.8-70.3)$ & $28.7(6.9-78.8)$ \\
Oestradiol $(\mathrm{pmol} / \mathrm{l})$ & $135(12-409)$ & $1095(266-2075)$ & $752(126-1484)$ \\
Progesterone $(\mathrm{ng} / \mathrm{ml})$ & $0.77(0.34-2.53)$ & $1.12(0.76-2.15)$ & $13.25(2.02-28.8)$ \\
Testosterone $(\mathrm{ng} / \mathrm{ml})$ & $0.47(0.17-1.48)$ & $0.63(0.23-1.33)$ & $0.50(0.10-1.44)$ \\
\hline
\end{tabular}

$\dagger P=0.04$ compared to the early follicular phase (Mann-Whitney U-test). 


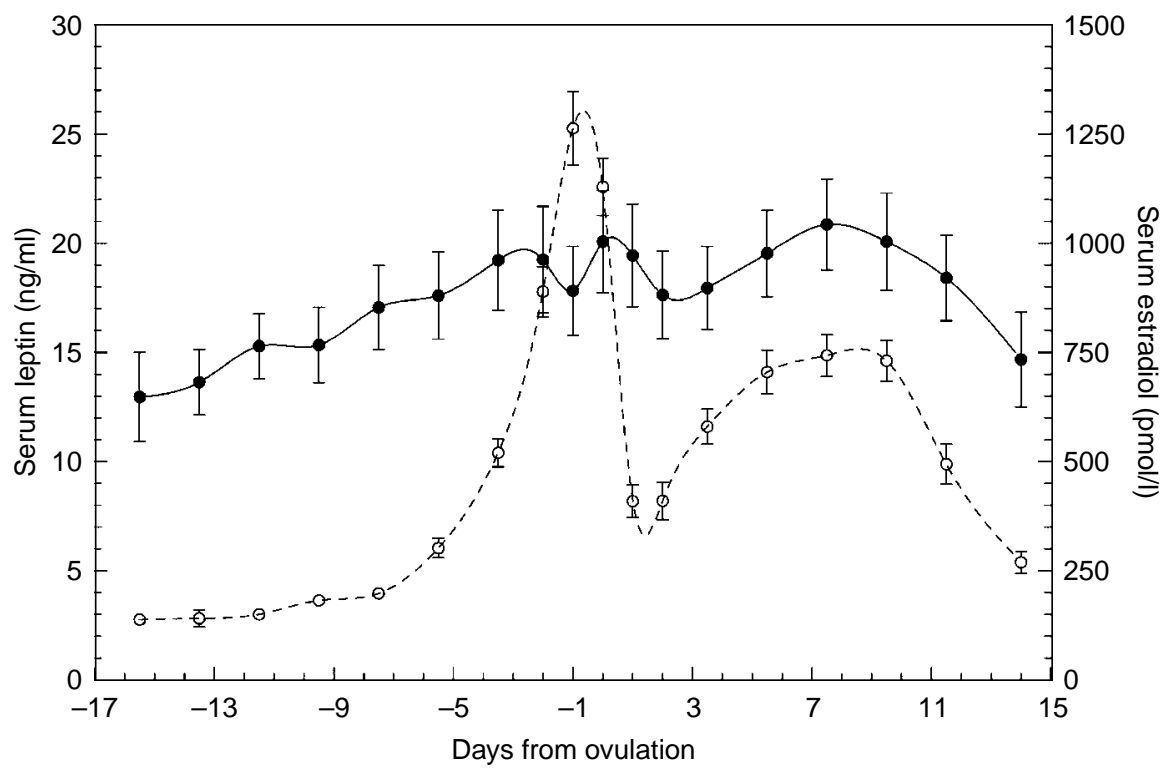

Figure 1 Concentrations of circulating leptin $(\bullet)$ and oestradiol $(\bigcirc)$ during the normal ovulatory menstrual cycle in 36 healthy women. Values shown are means \pm S.E.M. The curve shown was smoothed using the cubic spline (4-value) algorithm.

predominate in the literature. Some publications and some authors described correlations between leptin and oestrogens (11) or progesterone (15), whereas a majority of reports find no correlations at all $(9,10$, $14,16,18,21)$. One publication reported an association between leptin and LH (19), but in that study (19) only six normal-weight women at only three-defined time points have been evaluated. In contrast, in our study, blood samples were taken at least every other day during a full menstrual cycle in 36 women. Therefore, the considerable differences in the number of patients included have to be taken into consideration. There are also differences in the assay methodologies; while in many older studies CRP was

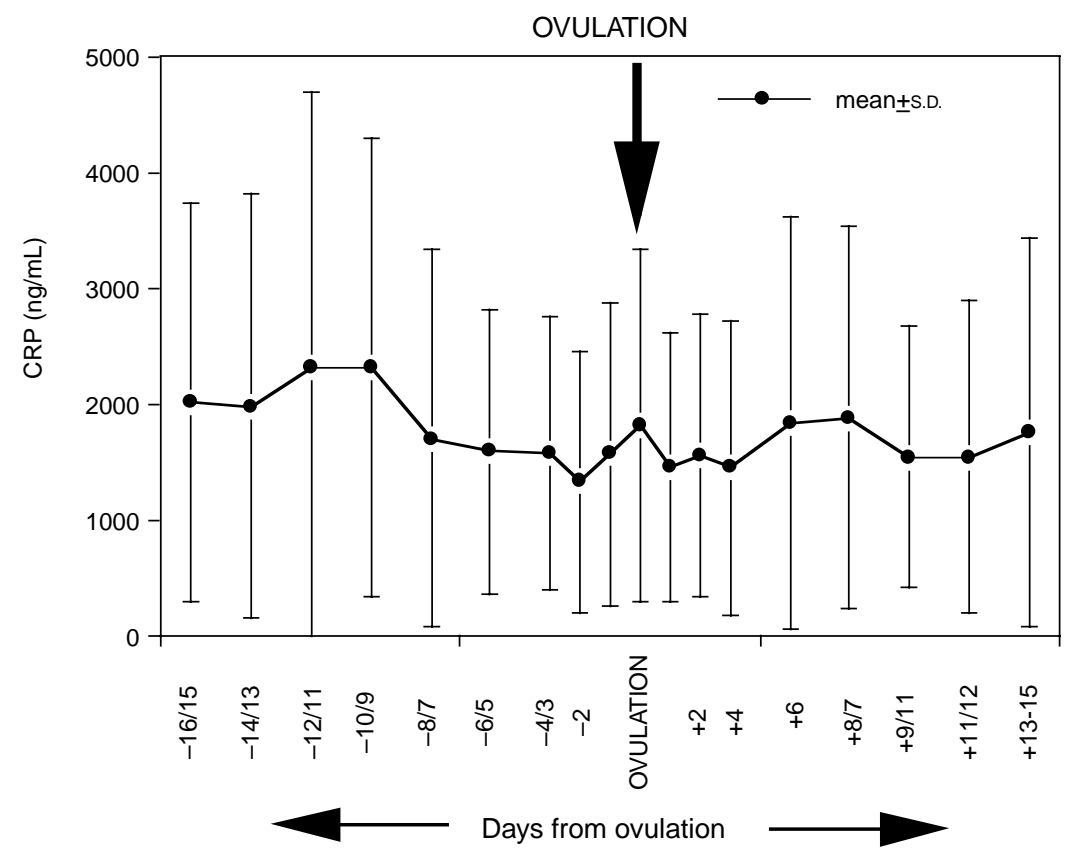

Figure 2 Concentrations of circulating CRP during the normal ovulatory menstrual cycle in 33 healthy women. Values shown are means \pm S.E.M. The curve shown was smoothed using the cubic spline (4-value) algorithm. 
determined by a nephelometric method, we used the more recently validated and highly sensitive ELISA method (33). In our study presented here, precisely timed measurements were performed every day or every second day of the cycle with 36 Caucasian women. In the follicular phase, we could find a parallel of leptin, PRL $(P=0.028)$ and free testosterone $(P=0.005)$. Although it is well known that free testosterone and PRL rise during follicular maturation, there is no causative explanation for the correlation between leptin and follicular maturation. No correlations between sex steroids, PRL and leptin were found in the luteal phase. Concerning the inflammatory mediator CRP, only a few trials with low number of subjects have been studying its concentration pattern during the normal spontaneous cycle. Blum et al. (30) recently investigated eight young, normal-weight women with normal ovarian function and found that CRP concentrations changed significantly during the menstrual cycle. Concentrations were highest in the early follicular phase and inversely correlated to E2 concentrations. In the present study, we could not confirm cycle-dependent CRP variations in a clearly larger patient group and we did not find any correlation with E2. The differences between the results of Blum et al. (30) and the present data can most likely be explained by the nearly four times larger sample size and the slightly shorter (and thus more sensitive) intervals between samplings ( 2 days maximum) in our study. In another study on CRP levels in the menstrual cycle with 18 patients (29), a CRP increase of $44 \%$ at midcycle and $31 \%$ in the luteal phase in comparison to follicular phase levels were found. There was a significant correlation between the relative increase in CRP at midcycle and the relative increase in progesterone levels during midcycle and the luteal phase. This finding is also in contrast with our results; we could not find significant correlations between either the absolute concentrations of CRP and progesterone, or between their increments in the luteal phase. Knowing that CRP is an acute phase protein and that it is produced only a few hours after the onset of an inflammatory process, one could expect a cycle peak of CRP production around ovulation. On the other hand, the isolated, cycleindependent spikes in the three individuals in our sample could be explained by variables supposed to influence the CRP levels, such as physical activity $(34,35)$, consumption of coffee, stress (35) or genetic polymorphisms (36). The fact is intriguing that the pattern of CRP in the spontaneous cycle is completely different from the one observed in gonadotrophinstimulated in-vitro fertilization (IVF) cycles. As we have shown, there is a significant increase in CRP levels on the day of ovarian pick-up (OPU), compared to the day of ovulation induction or 1 day before (33). The timing of the blood sampling, taken immediately before the OPU procedure, corresponds to the period just before ovulation. The rise in CRP seems quite logical given that the ovulation is an inflammatory process. But these findings from IVF cycles do not concur with our present results from spontaneous menstrual cycles: in spontaneous, normal cycles there is no increase of CRP levels neither around the time of ovulation nor around the time of menstruation. This discrepancy might be explained by the supra-physiological E2 concentrations reached in assisted reproductive therapies. These high oestrogen levels may stimulate the production of CRP in the liver, resulting in a CRP pattern strongly different from the one seen in spontaneous, non-stimulated cycles. Similarly, elevated CRP levels have been found in women using oral contraceptives $(37,38)$ and also in women with tubal factor subfertility due to persistent Chlamydia trachomatis infection (39). Another theoretical explanation could be the fact that in contrast to physiological cycles, 5000-10 000 IU of human chorionic gonadotrophin (hCG) is administered in IVF treatment cycles. hCG could possibly have an impact on inflammatory reactions; however, precise data in the literature on this topic are missing. No association between CRP and leptin could be found neither in the present study (spontaneous menstrual cycles) nor in gonadotrophin-stimulated cycles (33). Considering that both these mediators are involved in inflammatory processes, the different concentration patterns indicate the presence of complex mechanisms. We conclude that in the menstrual cycle, CRP as an inflammatory marker and leptin in its role as an inflammatory mediator follow different concentration patterns. The inflammatorymediating effects of leptin and CRP are unrelated to each other. Cycle-dependent fluctuations of leptin might be important in the diagnosis of metabolic dysfunctions, whereas there is no cycle-dependence for CRP. Therefore, CRP levels of fertile women in daily routine do not have to be evaluated in function of the menstrual cycle.

\section{Acknowledgements}

Our thanks go to Anne Vaucher for technical assistance in the running of the immunoassays.

\section{References}

1 Lord GM, Matarese G, Howard JK, Baker RJ, Bloom SR \& Lechler RI. Leptin modulates the T-cell immune response and reverses starvation-induced immunosuppression. Nature 1998 394 897-901.

2 Janik JE, Curti BD, Considine RV, Rager HC, Powers GC, Alvord WG, Smith JW 2nd, Gause BL \& Kopp WC. Interleukin-1alpha increases serum leptin concentrations in humans. Journal of Clinical Endocrinology and Metabolism 199782 3083-3086.

3 Sierra-Honigmann MR, Nath AK \& Murakami C. Biological action of leptin as an angiogenic factor. Science $1998 \mathbf{2 8 1} 1683-1686$.

4 Masuzaki H, Ogawa Y, Sagawa N, Hosoda K, Matsumoto T, Mise H, Nishimura H, Yoshimasa Y, Tanaka I, Mori T \& Nakao K. Nonadipose tissue production of leptin: leptin as a novel placentaderived hormone in humans. Nature Medicine 19973 1029-1033. 
5 Matarese G, Alviggi C, Sanna V, Howard JK, Lord GM, Carravetta C, Fontana S, Lechler RI, Bloom SR \& De Placido G. Increased leptin levels in serum and peritoneal fluid of patients with pelvic endometriosis. Journal of Clinical Endocrinology and Metabolism 200085 2483-2487.

6 Barash IA, Cheung CC, Weigle DS, Ren H, Kabigting EB, Kuijper JL, Clifton DK \& Steiner RA. Leptin is a metabolic signal to the reproductive system. Endocrinology 1996137 3144-3147.

7 Brzechffa PR, Jakimiuk AJ, Agarwal SK, Weitsman SR, Buyalos RP \& Magoffin DA. Serum immunoreactive leptin concentrations in women with polycystic ovary syndrome. Journal of Clinical Endocrinology and Metabolism 199681 4166-4169.

8 Saraff P, Frederich RC, Turner EM, Ma G, Jaskowiac NT, Rivet DJ 3rd, Flier JS, Lowell BB, Fraker DL \& Alexander HR. Multiple cytokines and acute inflammation raise mouse leptin levels: potential role in inflammatory anorexia. Journal of Experimental Medicine $1997 \mathbf{1 8 5} 171-175$.

9 Mannucci E, Ognibene A, Becorpi A, Cremasco F, Pellegrini S, Ottanelli S, Rizzello SM, Massi G, Messeri G \& Rotella CM. Relationship between leptin and oestrogens in healthy women. European Journal of Endocrinology 1998139 198-201.

10 Riad-Gabriel MG, Jinagouda SD, Sharma A, Boyadjian R \& Saad MF. Changes in plasma leptin during the menstrual cycle. European Journal of Endocrinology $1998139528-531$.

11 Messinis IE, Milingos S, Zikopoulos K, Kollios G, Seferiadis K \& Lolis D. Leptin concentrations in the follicular phase of spontaneous cycles and cycles superovulated with follicle stimulating hormone. Human Reproduction 199813 1152-1156.

12 Fernandez-Real JM, Gutierrez C, Vendrell J, Casamitjana R \& Ricart W. Plasma soluble tumor necrosis factor-alpha receptors circulate in proportion to leptin levels during the menstrual cycle in lean but not in obese women. European Journal of Endocrinology $2000143235-241$.

13 Geisthövel F, Jochmann N, Widjaja A, Horn R \& Brabant G. Serum pattern of circulating free leptin, bound leptin, and soluble leptin receptor in the physiological menstrual cycle. Fertility and Sterility $200481398-402$.

14 Ludwig M, Klein HH, Diedrich K \& Ortmann O. Serum leptin concentrations thoughout the menstrual cycle. Archives of Gynecology and Obstetrics 2000263 99-101.

15 Hardie L, Trayhurn P, Abramovich D \& Fowler P. Circulating leptin in women: a longitudinal study in the menstrual cycle and during pregnancy. Clinical Endocrinology 199747 101-106.

16 Quinton ND, Laird SM, Okon MA, Li TC, Smith RF, Ross RJ \& Blakemore AI. Serum leptin levels during the menstrual cycle of healthy fertile women. British Journal of Biomedical Science 1999 56 16-19.

17 Lukaszuk K, Liss J, Kusiak E \& Wojcikowski C. Serum leptin concentration increase during luteal phase in healthy premenopausal women. Hormone and Metabolic Research $199830172-173$.

18 Stock SM, Sande EM \& Bremme KA. Leptin levels vary significantly during the menstrual cycle, pregnancy, and in vitro fertilization treatment: possible relation to estradiol. Fertility and Sterility 1999 72 657-662.

19 Teirmaa T, Luukkaa V, Rouru J, Koulu M \& Huupponen R. Correlation between circulating leptin and luteinizing hormone during the menstrual cycle in normal-weight women. European Journal of Endocrinology 1998139 190-194.

20 Yamada M, Irahara M, Tezuka M, Murakami T, Shima K \& Aono T. Serum leptin profiles in the normal menstrual cycles and gonadotrophin treatment cycles. Gynecologic and Obstetrical Investigation 200049 119-223.

21 Lin KC. Changes of circulating leptin levels during normal menstrual cycle: relationship to estradiol and progesterone. Kaohsiung Journal of Medical Science 199915 597-602.

22 Mendall MA, Patel P, Ballam L, Strachan D \& Northfield TC. C-reactive protein and its relation to cardiovascular risk factors: A population based cross sectional study. British Medical Journal $19963121061-1065$.
23 Ford ES. Body mass index, diabetes and C-reactive protein among U.S. adults. Diabetes Care 199922 1971-1977.

24 Visser M, Bouter LM, McQuillan GM, Wener MH \& Harris TB. Elevated C-reactive protein levels in overweight and obese adults. Journal of the American Medical Association 1999282 2131-2135.

25 Yudkin JS, Stehouwer CD, Emeis JJ \& Coppack SW. C-reactive protein in healthy subjects: associations with obesity, insulin resistance, and endothelial dysfunction: a potential role for cytokines originating from adipose tissue? Arteriosclerosis, Thrombosis, and Vascular Biology 199919 972-978.

26 Shamsuzzaman AS, Winnicki M, Wolk R, Svatikova A, Phillips BG, Davison DE, Berger PB \& Somers VK. Independent association between plasma leptin and C-reactive protein in healthy humans. Circulation 2004109 2181-2185.

27 Bullo M, Garcia-Lorda P, Megias I \& Salas-Salvado J. Systemic inflammation, adipose tissue tumor necrosis factor, and leptin expression. Obesity Research 200311 525-531.

28 Maruna P, Gürlich R, Frasko R \& Haluzik M. Serum leptin levels in septic men correlate well with C-reactive protein (CRP) and TNFalpha but not with BMI. Physiological Research 200150 589-594.

29 Jilma B, Dirnberger E, Loscher I, Rumplmayr A, Hildebrandt J, Eichler HG, Kapiotis S \& Wagner OF. Menstrual cycle-associated changes in blood levels of interleukin-6, alpha 1 acid glycoprotein, and C-reactive protein. Journal of Laboratory and Clinical Medicine $199713069-75$.

30 Blum CA, Müller B, Huber P, Kraenzlin M, Schindler C, De Geyter C, Keller U \& Puder JJ. Low-grade inflammation and estimates of insulin resistance during the menstrual cycle in lean and overweight women. Journal of Clinical Endocrinology and Metabolism $2005903230-3235$.

31 Malek A, Willi A, Muller J, Sager R \& Bersinger N. Capacity for hormone production of cultured trophoblast cells obtained from placentae at term and in early pregnancy. Journal of Assisted Reproduction and Genetics 200118 299-303.

32 Flower L, Ahuja RH, Humphries SE \& Mohammed-Ali V. Effects of sample handling on the stability of interleukin-6, tumour necrosis factor-alpha and leptin. Cytokine 200012 1712-1716.

33 Wunder D, Kretschmer R \& Bersinger NA. Concentrations of leptin and C-reactive protein in serum and follicular fluid during assisted reproductive cycles. Human Reproduction 2005 20 1266-1271.

34 Stauffer BL, Hoetzer GL, Smith DT \& DeSouza CA. Plasma Creactive protein is not elevated in physically active postmenopausal women taking hormone replacement therapy. Journal of Applied Physiology 200496 143-148.

35 De Maat MP \& Kluft C. Determinants of C-reactive protein concentration in blood. Italian Heart Journal 20012 189-195.

36 Suk HJ, Ridker PM, Cook NR \& Zee RY. Relation of polymorphism within the C-reactive protein gene and plasma CRP levels. Atherosclerosis $2005 \mathbf{1 7 8} 139-145$.

37 Williams MJ, Williams SM, Milne BJ, Hancox RJ \& Poulton R. Association between C-reactive protein, metabolic cardiovascular risk factors, obesity and oral contraceptive use in young adults. Internal Journal of Obesity Related Metabolic Disorders 200428 998-1003.

38 Kluft C, Leuven JA, Helmerhorst FM \& Krans HM. Pro-inflammatory effects of oestrogens during use of oral contraceptives and hormone replacement treatment. Vascular Pharmacology 200239 149-154.

39 den Hartlog JE, Land JA, Stassen FR, Kessels AG \& Bruggeman CA. Serological markers of persistent C. trachomatis infections in women with tubal factor subfertility. Human Reproduction $2005 \mathbf{2 0}$ 986-990.

Received 15 December 2005

Accepted 6 April 2006 